REVIEW ARTICLE

\title{
Autonomic Innervation Evaluation in Cardiac Disease
}

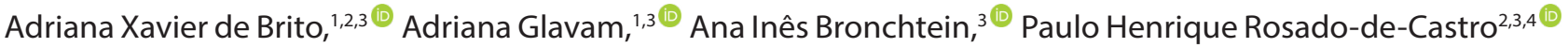 \\ Instituto Nacional de Cardiologia - Medicina Nuclear, ${ }^{1}$ Rio de Janeiro, RJ - Brazil \\ IDOR, ${ }^{2}$ Rio de Janeiro, RJ - Brazil \\ Rede D'Or São Luiz, ${ }^{3}$ Rio de Janeiro, RJ - Brazil \\ Universidade Federal do Rio de Janeiro, ${ }^{4}$ Rio de Janeiro, $R J$ - Brazil
}

\section{Abstract}

Cardiovascular diseases are among the leading causes of mortality and morbidity in the world. In different cardiac diseases, the neuronal function of the heart is impaired. Nevertheless, the development of a simple method to assess the autonomic effects on the heart and/or autonomic dysfunction is a challenge. The evaluation of autonomic innervation in cardiac diseases has helped to improve the knowledge of the pathophysiology of these conditions, as well as to provide information on their prognosis. Single photon emission computed tomography (SPECT) and positron emission tomography (PET) are currently the only imaging methods that allow in vivo assessment of cardiac innervation. The majority of SPECT and PET radiotracers evaluate sympathetic neuronal integrity using presynaptic imaging agents that are either labeled as endogenous transmitters or analogues. Postsynaptic imaging agents have also been developed to study sympathetic neuronal integrity, as well as tracers to investigate the parasympathetic nervous system. These methods may be used to analyze the innervation of the heart and allow for early detection of abnormalities caused by, for example, ischemia, heart failure, cardiomyopathies, cardiotoxicity, and arrhythmogenic disorders. This review provides an overview of cardiac innervation evaluation and their application in the assessment of heart disease.

\section{Keywords}

Autonomic Denervation; Heart Failure; Diagnostic, IImaging; Myocardial Ischemia; Autonomic Nervous System.

\section{Introduction}

Cardiovascular diseases (CVD) have been considered the leading cause of death and one of the most critical global public health problems. Although cardiovascular mortality in highincome countries is decreasing, sudden cardiac death (SCD) still constitutes a substantial part of cardiovascular mortality, with an estimated 4 to 5 million cases per year worldwide. ${ }^{1}$

Sympathetic innervation plays an important role in controlling myocardial blood flow, heart rate, and contraction of heart performance. In several cardiac diseases, the neuronal function of the heart is altered and neuronal cardiac imaging can help to improve the knowledge of the pathophysiology of these diseases, especially in SCD.

Single photon emission computed tomography (SPECT) and positron emission tomography (PET) are currently the only imaging methods that allow for an in vivo assessment of cardiac innervation. The majority of SPECT and PET radiotracers evaluate sympathetic neuronal integrity, using presynaptic imaging agents that are either labeled as endogenous transmitters or analogues. Postsynaptic imaging agents have also been developed to study sympathetic neuronal integrity, as well as tracers to investigate the parasympathetic nervous system. Several diagnostic methods that do not involve imaging have also been applied in the assessment of cardiac dysautonomia.

The purpose of this article is to provide a review of published data on the evaluation of cardiac autonomic innervation by image and its application in various heart diseases.

\section{Autonomic Nervous System}

The autonomic nervous system (ANS) is broad and extends to most organic systems. Therefore, the study of 
autonomic function is usually linked to a final organ of specific interest. Functional autonomic outputs, defined by the sympathetic and parasympathetic systems provide a strongly integrated combination of homeostasis control. ${ }^{2}$

The ANS is closely linked to many behaviors, emotions, and the immune system. Some examples include changes in the cardiorespiratory response orchestrated during exercise, when trying to escape from a threatening environment, when facing a situation of fear, during an inflammatory response, or even when simply moving from the supine to the vertical position. In the heart, cardiac sympathetic and parasympathetic nervous systems (SNS) work by exerting essentially opposite responses. These branches differ in their neurotransmitters and use stimulatory or inhibitory effects on the target tissue through adrenergic and muscarinic receptors ${ }^{2}$ (Figure 1 ).

The two mediators of the SNS, norepinephrine (NE) and epinephrine are derived from two main sources in the body: the sympathetic nerve endings, which release NE directly into the synaptic cleft, and the adrenal medulla, whose chromatin cells predominantly synthesize, store and release epinephrine, ${ }^{3} \mathrm{NE}$ is released in the synaptic clefts in response to neuronal stimulation through the fusion of presynaptic storage vesicles with the neuronal membrane. It stimulates presynaptic cardiac $\alpha 2$ adrenergic receptors (ARs), which provide negative feedback on exocytosis and postsynaptic $\beta$-ARs. In the synaptic cleft, most NE undergoes resorption at the nerve terminals by the NE presynaptic transporter and recycles into vesicles or is metabolized in the cytosol by the monoamine oxidase enzyme. The overflow of NE can also be measured in the blood and used to infer a sympathetic flow to the heart. ${ }^{4}$

Acetylcholine (ACh), the neurotransmitter of the parasympathetic system, is stored in the vesicles and is released by parasympathetic stimulus, activating the muscarinic and pre-ganglionic postsynaptic receptors. Parasympathetic stimulation decreases the heart rate, reducing the discharge rate of the sinoatrial node and the conduction velocity of the atrioventricular node, with minimal or no effect on cardiac contractility. ${ }^{5}$

ANS dysfunction may result from primary disorders of the autonomic nerves or secondarily in response to heart or systemic diseases. These changes can occur in several interrelated cardiac conditions, including hypertension, myocardial ischemia, heart failure (HF), cardiac arrhythmias and SCD. ${ }^{6}$ Adrenergic beta-blockers are the most established autonomic intervention. Other interventions (for example, cardiac sympathetic denervation) have shown promise for the treatment of refractory ventricular arrhythmias. ${ }^{7}$

Much has been studied about the complex interactions along the neuroaxis and its role in cardiac control. However, the development of a simple method to assess the autonomic effects on the heart and/or autonomic dysfunction is a challenge. There are several exams that evaluate the autonomic function. Even though many methods have demonstrated some prognostic value, none have yet been implemented in clinical practice.

\section{Flowchart of research execution}

\section{Methodology}

A comprehensive literature review of articles published in the following databases was performed: PubMed and Medline. The following terms used were: autonomic innervation evaluation (AND) cardiac disease. Through the evaluation of abstracts, articles that were not related to the topic were excluded.

\section{Results}

The search with the combination of all the terms listed above returned 602 articles in a search carried out until May 15, 2020. Only articles in the English language and human species were selected. A total of 184 articles were selected according to the visual analysis of correlation with the topic studied between the years 1980 and 2020, after excluding duplicate articles. Approximately 50\% of the articles were published in the last 10 years.

Imaging techniques used to assess autonomic innervation:

The following imaging techniques have been used to assess ANS activity: SPECT and PET.

Metaiodobenzylguanidine ( ${ }^{123}$ I-MIBG) SinglePhoton Emission Computed Tomography (SPECT)

Metaiodobenzylguanidine (MIBG) was discovered in 1980 to search for tumors of the adrenal medulla. MIBG is an NE analogue with a similar molecular structure. It is captured via the norepinephrine transporter 1 (uptake-1 mechanism) and stored in presynaptic neurosecretory vesicles. ${ }^{8}$ After adrenergic stimulation, MIBG is 


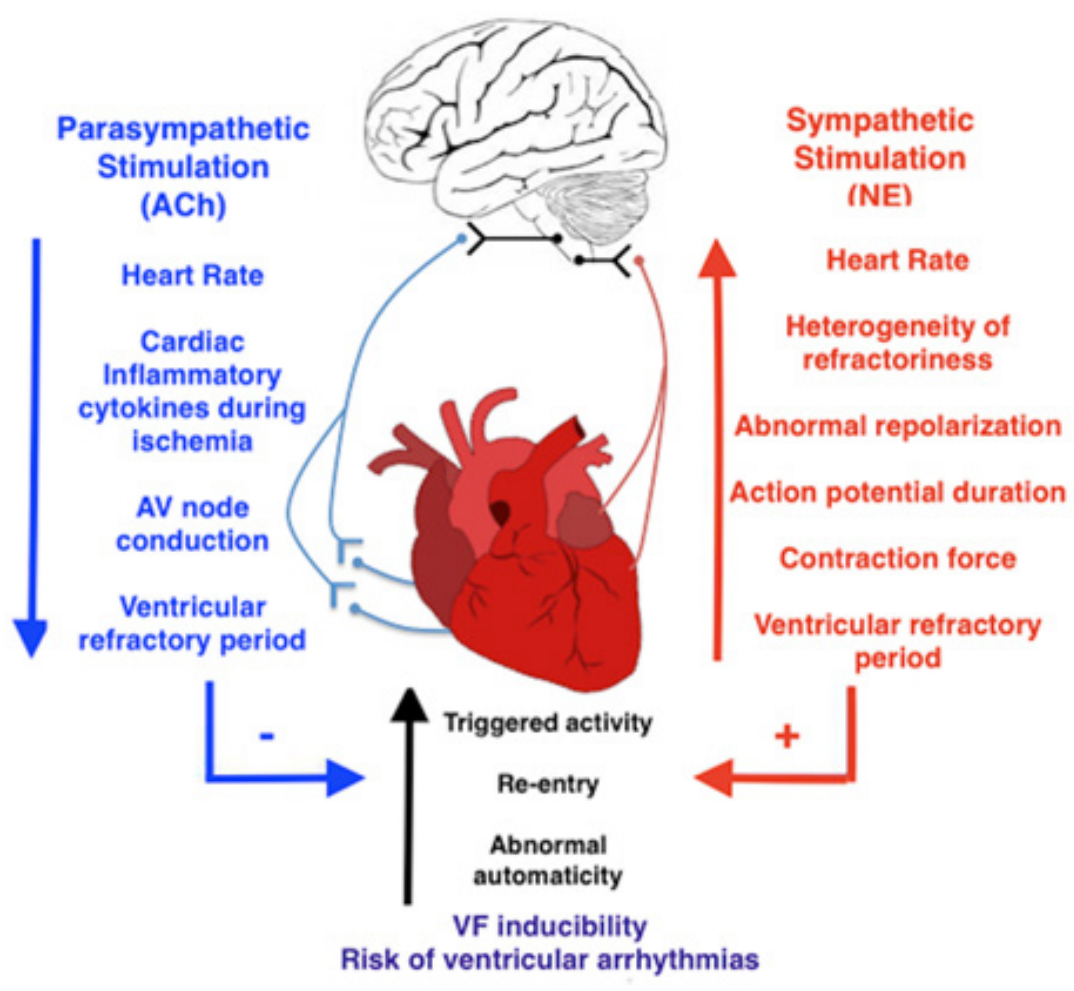

Figure 1 - The sympathetic and parasympathetic nervous system - arrhythmogenic effects on the heart. Adapted from Franciosi et al. ${ }^{17}$

released into the synaptic cleft, but it has low affinity for postsynaptic receptors without pharmacological action and is not metabolized by monoamine oxidase (MAO) nor catechol-o-methyltransferase (COMT) enzymes. In contrast to NE, MIBG is stored for several hours without being metabolized, allowing the acquisition of images. MIBG uptake has been shown to correlate with NE concentration in vivo, representing cardiac SNS innervation under physiological and pathological conditions ${ }^{9,10}$ (Figure 2).

Iodine-123-labeled MIBG ( ${ }^{123} \mathrm{I}-\mathrm{MIBG}$ ) allows for the visualization of cardiac sympathetic innervation by SPECT technology and makes it possible to evaluate and quantify the radiotracer distribution in the myocardium. Calculations of early and late heart-mediastinum ratio (HMR) and washout rate (WO) are performed.

Early HMR represents the integrity of the presynaptic nerve terminals and the density of $\beta$-ARs; late HMR combines neural function information, including NE uptake, release, and storage in presynaptic vesicles; and the $\mathrm{WO}$ reflects the adrenergic tone. ${ }^{11}$

The role of ${ }^{123}$ I-MIBG has been well studied in several clinical conditions, with prognostic value in heart failure, ischemic heart disease, ventricular arrhythmias, and cardiomyopathies.

\section{Positron Emission Tomography (PET)}

PET imaging offers several advantages over SPECT, including superior image resolution, allowing for a more specific regional analysis of the function of cardiac neurons. ${ }^{12}$ The PET examination facilitates the combined assessment of myocardial viability and perfusion together with innervation. It also offers the potential for imaging using autonomic receptors, as well as the global quantification of cardiac sympathetic and parasympathetic activity.

The most studied radiotracer for the neuronal evaluation conducted by the PET technique in humans is carbon-11 $\left({ }^{11} \mathrm{C}\right)$-labeled meta-hydroxyephedrine $\left({ }^{11} \mathrm{C}-\mathrm{HED}\right)$, an analogue to NE and ${ }^{123} \mathrm{I}-\mathrm{MIBG}$, which is transported by the uptake-1 mechanism.

Other agents have been researched for their role in the direct visualization of adrenergic receptors. Examples include ${ }^{11} \mathrm{C}$-CGP12177 and ${ }^{11} \mathrm{C}-\mathrm{CGP} 12388$. Both analogues were studied for their role in assessing the density of $\beta$-ARs in normal and diseased hearts using PET images, and are promising in predicting results and guiding treatment in ischemic heart disease and HF. ${ }^{13,14}$ 


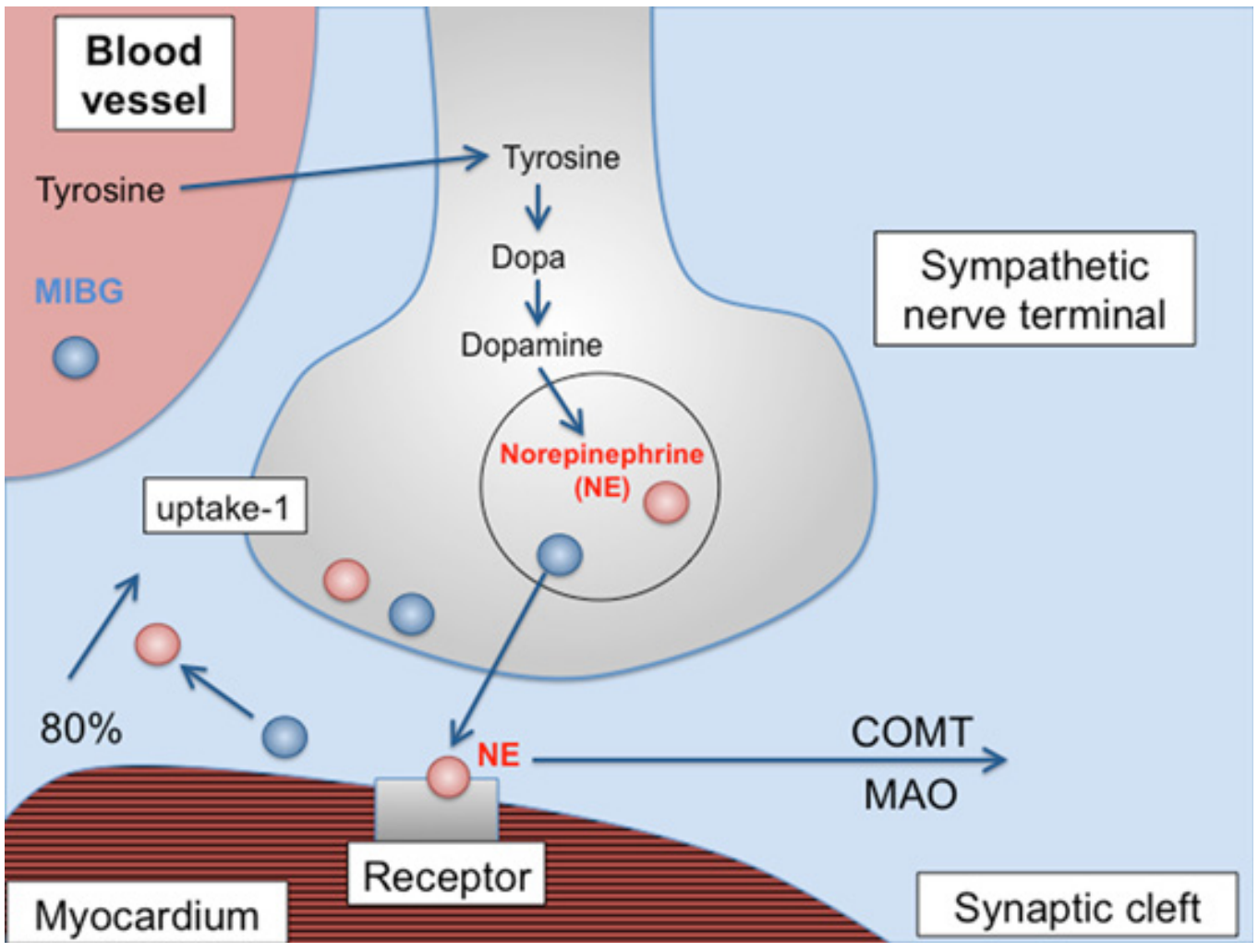

Figure 2 - Norepinephrine and MIBG metabolic pathways in the sympathetic cardiac nerve terminal.

However, the main current limitations for assessing innervation by PET technology are the higher costs when compared to SPECT and shorter half-lives of radioisotopes, some of which require on-site cyclotrons for production, such as ${ }^{11} \mathrm{C} \cdot{ }^{15}$ Consequently, very few centers perform cardiac sympathetic neuroimaging using the PET scan.

\section{Neuronal imaging in heart disease}

\section{Heart Failure (HF)}

In $\mathrm{HF}$, it is possible to maintain blood flow to the vital organs during states of low cardiac output thanks to the activation of the sympathetic nervous systems, reninangiotensin-aldosterone, and antidiuretic mechanism. ${ }^{16}$

Prolonged exposure to NE leads to peripheral vasoconstriction, sodium and water retention, activation of the renin-angiotensin neurohumoral system, and desensitization of $\beta$-adrenergic postsynaptic receptors, which can cause malignant arrhythmias and SCD, or ventricular remodeling with insufficiency progression due to direct toxicity, interleukin, and TNF $\alpha$ system expressions and consequent apoptosis. When facing persistent high concentrations of circulating NE, the heart undergoes blockage of its $\beta$-adrenergic agonist receptors. Several mechanisms can contribute to this phenomenon, such as $\beta$-adrenergic receptor down regulation, non-coupling of $\beta$-receptor subtypes, upregulation of the $\beta$-adrenoreceptor kinase enzyme, increased G-protein and reduced adenylcyclase activity. Ventricular remodeling itself, which involves hypertrophy and myocyte apoptosis caused by NE, is associated with the re-expression of fetal genes with consequent downregulation of adult genes. This demonstrates the toxicity of chronic direct stimulation of $\beta$-adrenergic receptors in myocytes and fibroblasts and contributes to several biochemical and structural changes in HF. ${ }^{17-21}$

${ }^{123}$ I-MIBG SPECT is characterized by reduced uptake and increased washout of the radiotracer in patients with HF compared to healthy individuals.

Several prognostic studies have shown that abnormal HMR as well as accelerated washout are independent 


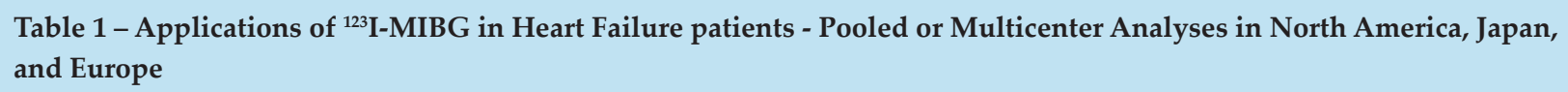

\begin{tabular}{|c|c|c|c|c|c|c|c|c|c|}
\hline Study & Year & $\begin{array}{c}\text { № of } \\
\text { patients }\end{array}$ & $\begin{array}{l}\text { Subjects } \\
\text { included }\end{array}$ & $\begin{array}{c}\text { Follow-up } \\
\text { (mean) }\end{array}$ & $\begin{array}{c}\text { HMR } \\
\text { threshold } \\
\text { on123I- } \\
\text { MIBG } \\
\text { studies }\end{array}$ & $\begin{array}{c}\text { Multivariate } \\
\text { analysis }\end{array}$ & Endpoint & $\begin{array}{l}\text { Cardiac } \\
\text { events }\end{array}$ & $\begin{array}{l}\text { Cardiac } \\
\text { death }\end{array}$ \\
\hline $\begin{array}{l}\text { Jacobson } \\
\text { et al. (41) }\end{array}$ & 2010 & 961 & $\begin{array}{c}\text { NYHA class } \\
2 \text { or } 3 \text {; LVEF } \\
\quad<35 \%\end{array}$ & $17 \mathrm{mo}$ & 1.60 & $\begin{array}{c}\text { HMR; LVEF; } \\
\text { NYHA class; } \\
\text { BNP }\end{array}$ & $\begin{array}{c}\text { Death; } \\
\text { progressive } \\
\text { HF; life } \\
\text { threatening } \\
\text { arrhythmia }\end{array}$ & $\begin{array}{l}\text { ACD: 81; } \\
\text { CD: 53; } \\
\text { arrhythmia: } \\
\quad 64\end{array}$ & $5.5 \%$ \\
\hline $\begin{array}{l}\text { Nakata et } \\
\text { al. (26) }\end{array}$ & 2013 & 1,322 & $\begin{array}{c}6 \text { cohort } \\
\text { studies; } \\
\text { pooled data }\end{array}$ & $77.6 \mathrm{mo}$ & 1.68 & $\begin{array}{l}\text { NYHA class; } \\
\text { age; HMR on } \\
\text { 123I-MIBG } \\
\text { studies; LVEF }\end{array}$ & Death & $\begin{array}{l}\text { ACD: } 326 ; \\
\text { CD: } 263\end{array}$ & $24.7 \%$ \\
\hline $\begin{array}{l}\text { Verschure } \\
\text { et al. (31) }\end{array}$ & 2014 & 636 & $\begin{array}{l}8 \text { studies } \\
\text { for meta- } \\
\text { analysis }\end{array}$ & $36.9 \mathrm{mo}$ & $\begin{array}{l}\text { Continuous } \\
\text { variable }\end{array}$ & $\begin{array}{l}\text { HMR; LVEF; } \\
\text { age for ACD }\end{array}$ & $\begin{array}{l}\text { Death; life- } \\
\text { threatening } \\
\text { arrhythmia; } \\
\text { heart } \\
\text { transplant }\end{array}$ & $\begin{array}{l}\text { ACD: 83; } \\
\text { CD: 67; } \\
\text { arrhythmia: } \\
\text { 33; heart } \\
\text { transplant: } \\
\quad 56\end{array}$ & $10.5 \%$ \\
\hline
\end{tabular}

CD: cardiac death; ACD: all-cause death; HMR: heart-mediastinum ratio; LVEF: left ventricular ejection fraction; NYHA: New York Heart Association; BNP: brain natriuretic peptide; HF: heart failure

predictors of death in patients with left ventricular (LV) dysfunction, even better than left ventricular ejection fraction (LVEF), New York Heart Association (NYHA) functional class, the size of the ventricle, and plasma NE values. ${ }^{22-29}$

A meta-analysis of 18 studies, including 1,755 patients, indicated that HF patients with reduced late ${ }^{123}$-MIBG HMR or increased WO had a worse prognosis when compared to those with normal ${ }^{123}$ I-MIBG uptake and WO. ${ }^{30}$

This same group demonstrated the independent prognostic value of increased cardiac sympathetic activity by the late HMR as a measure of ${ }^{123}$ I-MIBG myocardial uptake when used as a continuous parameter in another meta-analysis of multiple single-centre cohort studies. ${ }^{31}$

Table 1 shows pooled or multicenter analyses of ${ }^{123}$ I-MIBG SPECT in the evaluation of HF patients' prognosis in North America, Japan, and Europe.

Regarding the therapeutic evaluation of ventricular dysfunction, numerous studies using ${ }^{123}$ I-MIBG imaging have shown that the use of beta-blockers, ACE inhibitors, and spironolactone can significantly improve SNS activity, with a significant impact on prognosis. ${ }^{23,24,30-35}$
Gould et al., ${ }^{36}$ investigated whether the use of the biventricular pacemaker would affect sympathetic activity in HF patients. The results showed that the use of the pacemaker increased early and late ${ }^{123}$ I-MIBG uptakes. These authors concluded that the use of this device in HF patients is associated with a significant improvement in cardiac SNS activity, and this must be the potential mechanism of benefits regading morbidity and mortality. ${ }^{36}$

Some authors have also correlated adrenergic denervation on ${ }^{123}$ I-MIBG imaging with abnormal heart rate recovery, ${ }^{37}$ heart rate variability, and $S C D$ in patients with left ventricular dysfunction, even in those with mild dysfunction and NYHA class I ${ }^{29,38,39}$ Akutsu et al., ${ }^{40}$ demonstrated that changes in the SNS were independent predictors of ventricular tachycardia (VT) and ventricular fibrillation (VF) recurrence in patients with a previous history of these arrhythmias. The authors concluded that the ${ }^{123}$ I-MIBG image may be a good option for screening high-risk patients of SCD. ${ }^{40}$

Finally, after the prospective and multicenter ADMIRE-HF trial results, ${ }^{123}$ I-MIBG was approved by the US Food \& Drug Administration for use in NYHA 
class II or III HF patients with $\mathrm{LVEF}=<35 \%$. The trial results showed that patients with a late $\mathrm{HMR}<1.6$ (low MIBG uptake) had a cardiac death rate of $19.1 \%$ versus $1.8 \%$ in the group with a late HMR $>=1.6$ (high uptake of MIBG), with a negative predictive value for this outcome, in two years, of $98.8 \%$, thus permitting the identification of individuals with a worse prognosis ${ }^{41}$ (Figure 3).

\section{Ischemic heart disease}

The exact mechanisms of ventricular arrhythmias in ischemic heart disease have been debated, and it has been recognized that scar tissue and the presence of myocardial ischemia may serve as a substrate. In myocardial infarction, ischemia acts as a trigger for ventricular arrhythmias by inducing electrical instability. Areas of slow conduction facilitate the development of reentrant tachycardia in the scar from the infarction.

Sympathetic neurons have proven to be more sensitive and take longer to recover from ischemic injury when compared to myocardial tissue. It has been postulated that denervated myocardial regions with preserved blood flow and viability may predispose to fatal ventricular arrhythmias. ${ }^{42}$ Although the pathophysiology is not yet clear, it has been suggested that denervated but viable myocardium may be hypersensitive to circulating catecholamines and may respond differently to sympathetic activation with more automaticity ${ }^{17,43}$ (Figure 4).
Klein et al., ${ }^{44}$ demonstrated the feasibility of integrating ${ }^{123} \mathrm{I}-\mathrm{MIBG}$ SPECT with voltage mapping for VT ablation in post-infarction patients. The areas defined as denervated by ${ }^{123}$ I-MIBG were 2.5 times larger than the scar identified by the mapping of bipolar tension, and all sites of VT ablation showed abnormal denervation defined by the ${ }^{123} \mathrm{I}$-MIBG SPECT. ${ }^{44}$

The PARAPET study sought to predict arrhythmic events using a ${ }^{11} \mathrm{C}$-HED PET study in 200 patients with ischemic cardiomyopathy. This study demonstrated that arrhythmic death or shock from the implanted cardiac defibrillator (ICD) for VT or VF was directly related to the severity/extent of abnormalities in ${ }^{11} \mathrm{C}-\mathrm{HED}$ PET scans, regardless of brain natriuretic peptides (BNP), clinical symptoms, or LVEF. ${ }^{45}$

The new European Society of Cardiology guidelines included the use of myocardial perfusion SPECT or PET to assess ischemia and myocardial viability. However, there is no mention of the possible usefulness of cardiac innervation tests. ${ }^{46}$ Despite several promising studies, there is a consensus that the data are still insufficient to replace those established in the guidelines.

\section{Ventricular Arrhythmias}

It is well-known that ventricular arrhythmias and SCD occur frequently in the vulnerable cardiac substrate context with a triggering event and can be induced by an increased sympathetic tone. ${ }^{17,43,47}$
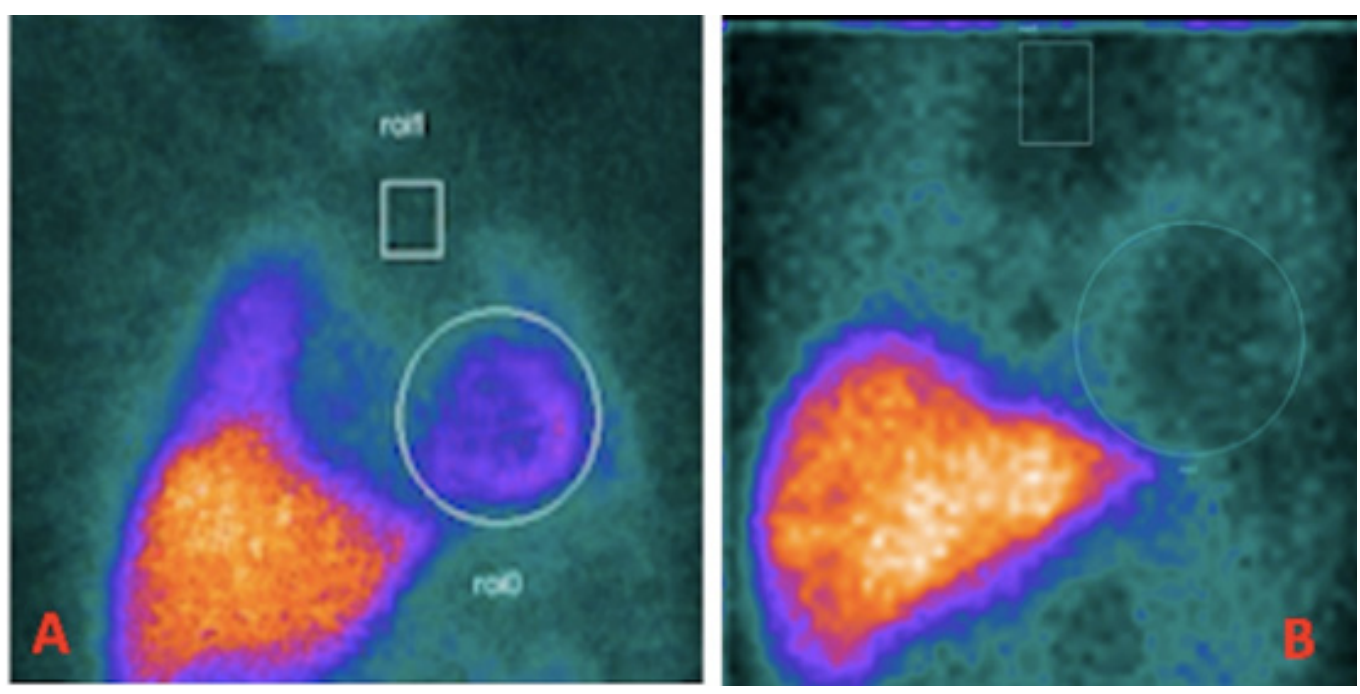

Figure 3 - ${ }^{123}$ I-MIBG imaging. Planar anterior chest images demonstrate: (A) normal uptake of the radiotracer; (B) absence of radiotracer uptake in cardiac topography in a patient with heart failure. 


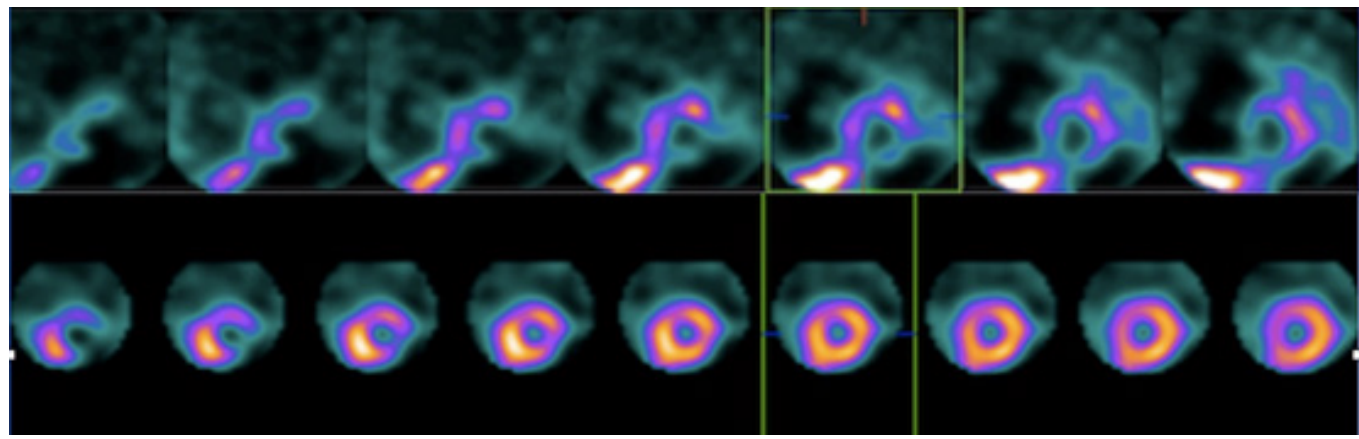

Figure 4 - Cardiac imaging in a patient with reduced innervation but relatively preserved perfusion. (A) short axis images of myocardial perfusion (lower row) and (B) ${ }^{123}$ I-MIBG uptake (upper row) indicate a lack of innervation in the apical, inferior, and lateral segments.

Current methods to identify risk of fatal arrhythmias are neither sensitive nor specific, and current patient selection practices for ICD are expensive. ${ }^{123} \mathrm{I}-\mathrm{MIBG}$ imaging was studied as a potentially useful tool in the prediction of ventricular arrhythmias and has shown promise in HF patients regarding the selection of defibrillator implantation.

Nagahara et al., ${ }^{48}$ investigated the role of ${ }^{123}$ I-MIBG imaging to predict arrhythmias in the setting of ICD therapy. In one study, ICD discharge was predicted by a combination of late HMR $<1.95$ together either LVEF $<50 \%$ or elevated BNP level. ${ }^{48}$ A second, prospective study from the same group examined the value of simultaneous innervation and perfusion imaging to predict arrhythmia, quantifying both ${ }^{123}$ I-MIBG and ${ }^{99 m}$ Technetium-tetrofosmin uptakes in 60 patients. Patients that received ICD shocks during follow-up presented a significantly lower HMR and more abnormal perfusion scores. ${ }^{49}$ Boogers et al. demonstrated that regional sympathetic denervation on late MIBG SPECT images was significantly associated with ventricular arrhythmia and appropriate ICD shock. In this study, the uptake defect score on ${ }^{123} \mathrm{I}$-MIBG late SPECT images was an independent predictor for adequate therapy with ICD. The risk for appropriate ICD shocks was 13 times higher in patients with large ${ }^{123}$ I-MIBG uptake defects than those with small defects. ${ }^{50}$

The subanalysis study of ADMIRE-HF also demonstrated that combined arrhythmic events (selflimited VT, resuscitated cardiac arrest, and appropriate ICD discharges) were more common in individuals with an $\mathrm{HMR}<1.60(10.4 \%)$ than those with HMR $>$ or $=1.6$ $(3.5 \% \mathrm{P}<0.01) .{ }^{41}$
Thus, cardiac ${ }^{123}$ I-MIBG imaging may enable cardiologists to identify patients who are most susceptible to lethal arrhythmias and event risks, and who can actually benefit most from device therapy by overcoming the limitations of current device therapy criteria, most of which consist of surrogate markers of lethal events, such as symptoms (NYHA class), clinical backgrounds, and LVEF. Nonetheless, this will depend on improvements in the technical consistency of clinical ${ }^{123}$ I-MIBG exams and a prospective generation of data documenting a positive effect of this procedure in clinically relevant situations.

\section{Takotsubo cardiomyopathy}

Takotsubo Cardiomyopathy (TC) also known as acute stress-induced cardiomyopathy is defined as a clinical condition characterized by an acute and transient $(<21$ days) LV systolic dysfunction that occurs mainly in post-menopausal women after emotional or physical distress. The classic pattern of regional LV wall motion abnormality is the apical (apical ballooning) with basal hyperkinesis present in up to $75-80 \%$ of the cases. ${ }^{51,52}$

It was originally recognized as a benign disease because of its typical transient nature; however, nowadays, non-negligible rates of life-threatening complications are also recognized. Moreover, the frequency of recurrence is practically irrelevant (1-2\% per-patient year) happening early or much later (up to 10 years) after the primary episode. ${ }^{53}$

Clinical manifestations are similar to acute coronary syndrome. Hence, a detailed anamnesis is essential to suspect TC, especially when an echocardiogram reveals a typical wall motion abnormality beyond the territory 
perfused by a single coronary artery. Nonetheless, most patients underwent coronary angiography to rule out obstructive coronary disease as the cause of acute systolic dysfunction..$^{51-53}$

Non-invasive methods, such as echocardiogram and cardiac magnetic resonance (CMR) have been used to assist in the diagnosis and follow-up of TC patients. ${ }^{53,54}$ The precise pathophysiology of this cardiomyopathy has not been completely understood. Nevertheless, a link between brain and heart has long been recognized. Hyperactivity of the SNS is the cornerstone in TC. ${ }^{51-}$ ${ }^{53}$ Emotional or physical distresses are triggers, and high plasma catecholamines levels are identified in the acute phase of the disease. Overload of catecholamines might be linked to cardiomyocyte cardiotoxicity and stunning. Results from animal studies displayed a higher density of $\beta 2-A R$ in apical than in basal ventricular cardiomyocytes. Thus, apical stunning could be evoked by excessive catecholamine stimulation. Therefore, stress cardiomyopathy represents a form of neurocardiogenic myocardial stunning, and nuclear medicine may play an important role in its evaluation..$^{55}$

${ }^{123}$ I-MIBG imaging is usually performed in the subacute phase of TC. Typical findings include impaired late HMR and WO obtained from planar imaging and reduced apical uptake on SPECT images correlating to impaired LV segments in the acute phase. ${ }^{56}$ More recently, some follow-up studies have unveiled promising data. One such study showed, after some months impaired, that a late HMR was increased and WO decreased significantly, while impaired apical uptake was not present. These findings reinforce the hypothesis that TC might be related to neurogenic myocardial stunning. The phenomenon underlying persistent reduced uptake on SPECT images is still unknown. The increased density and sensitivity of apical $\beta 2$-AR to catecholamines may well prolong downregulation and consequently impair the uptake- 1 mechanism. Whether those findings could be related to an increased chance of relapse or if $\beta$-blockers may be appropriate in the treatment is still undetermined $^{54,57,58}$ (Figure 5).

Ideally, a rest perfusion should also be performed mostly when CMR is not available. Normal or mild reduction of uptake is likely. Of note, ${ }^{11} \mathrm{C}$-HED PET data are scant. ${ }^{53,54,57}$

\section{Hypertrophic Cardiomyopathy}

Hypertrophic Cardiomyopathy (HC) is the most common heritable cardiomyopathy and is characterized by LV hypertrophy in absence of other possible causes. The anatomic hallmark of $\mathrm{HC}$ is a non-uniform LV hypertrophy, mainly of the interventricular septum. Several mutations in genes encoding sarcomere proteins have been uncovered, which impact phenotypic expression and prognosis. Diastolic dysfunction, dynamic LV outflow tract (LVOT) obstruction, mitral regurgitation, myocardial ischemia and arrhythmias are interrelated abnormalities commonly observed in HC patients. ${ }^{59}$

The echocardiogram has long been used to assess LV hypertrophy severity, a predictor of SCD risk. CMR should be considered as a baseline assessment of $\mathrm{HC}$ patients because of its superior spatial resolution, more accurate volumetric evaluation, better identification of apical aneurysms often related to ventricular

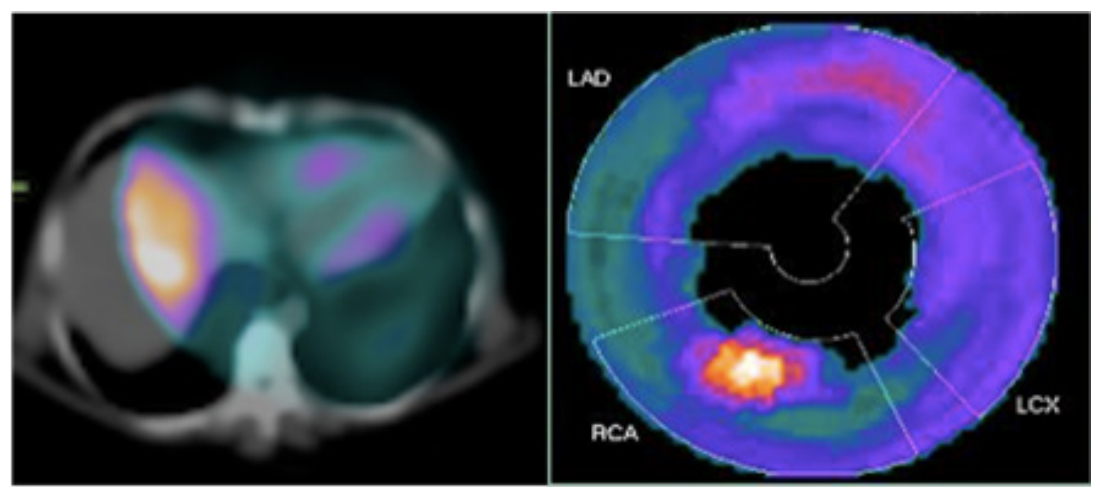

Figure 5 - Cardiac imaging in a patient with Takotsubo cardiomyopathy. (A) SPECT/CT showing ${ }^{123}$ I-MIBG distribution and the absence of apical uptake; (B) bulls-eye image showing ${ }^{123}$ I-MIBG distribution and the absence of apical uptake. LAD: left anterior descending coronary artery, RCA: right coronary artery, LCX: left circumflex coronary artery. 
arrhythmias, and, particularly, tissue characterization by late gadolinium enhancement (LGE). Prevalence of LGE is as high as $80 \%$ and a patchy, multifocal mid-wall LGE pattern in areas of hypertrophy suggests HC. Previous studies have revealed that LGE is useful in predicting cardiovascular mortality, but current data do not support LGE as an independent predictor of SCD risk. ${ }^{59}$

SCD may be the first manifestation in asymptomatic patients. The use of ICD for secondary prevention carries a class I indication in international guidelines. However, its use for primary prevention remains controversial. HC Risk-SCD Calculator incorporates LV hypertrophy, but not LGE. ${ }^{60,61}$

Clearly, it is mandatory to improve risk stratification in order to detect new outcome predictors. ${ }^{123}$ I-MIBG scintigraphy might be helpful in this scenario. Cardiac sympathetic activity is known to be impaired in $\mathrm{HC}$, and some studies have indicated a correlation between WO and echocardiogram features, such as hypertrophy severity, septum thickness, LVOT, and diastolic dysfunction. It is interesting to note that late HMR increased and consequent WO decreased in the months after septal ablation. ${ }^{55,62}$

\section{Cardiotoxicity evaluation}

The past years have led to significant improvements in cancer treatment. Nevertheless, old and novel therapies are known to cause cardiotoxicity. Among cancer survivors, secondary malignancies are reported as the leading cause of morbidity and mortality, followed closely by cardiotoxicity. Cardio-oncology is a developing specialty dedicated to understanding and preventing cardiovascular disease in cancer patients. In this context, non-invasive methods capable of screening subclinical cardiotoxicity are most needed. ${ }^{63,64}$

At first, cancer therapeutics-related cardiac dysfunction (CTRCD) was used to be allocated into two major groups: type I, related to cell death, irreversible, and normally dose dependent (anthracyclines), and type II, associated with myocyte dysfunction rather than apoptosis, potentially reversible, and not dose-dependent (trastuzumab). This kind of classification demonstrates that, initially, patient evaluation was solely related to LV dysfunction, but nowadays, other relevant parameters are also crucial. ${ }^{63,64}$

MUGA, echocardiogram, and CMR are recommended by several guidelines to regularly monitor LV function during chemotherapy. Since LV dysfunction is a late manifestation of cardiotoxicity, methods that precisely evaluate molecular damage might be extremely helpful ${ }^{63,64}$.

CTRCD induces a compensatory adrenergic response and ${ }^{123}$ I-MIBG imaging can identify it in advance detecting patients at increased risk. Some studies have shown reduced MIBG uptake in a dose-dependent way in patients receiving anthracycline treatment even before slight changes in LVEF. Two mechanisms might be involved: destruction of adrenergic nerve tissue or functional impairment. Another study valued the use of ${ }^{123} \mathrm{I}-\mathrm{MIBG}$ imaging in accessing trastuzumab-related CTRCD. In case of persistent CTRCD, the ${ }^{123}$ I-MIBG scan results might indicate whether recovery will occur and may be treatment reinitiated. ${ }^{65-67}$

Nowadays, ${ }^{18}$ F-fluorodeoxiglucose ( $\left.{ }^{18} \mathrm{~F}-\mathrm{FDG}\right)$ PET has been an extremely valuable technique in diagnosis, prognosis, and management treatment in cancer patients. However, clinical data assessing the role of PET in detecting CTRCD is still scarce. ${ }^{11} \mathrm{C}-\mathrm{HED}$, ${ }^{11} \mathrm{C}$-epineiphrine, and ${ }^{18} \mathrm{~F}$-6-fluordopamine and $(3 \mathrm{H})$ CGP12177 might be beneficial in the future. ${ }^{68}$

\section{Chagas Cardiomyopathy}

Chagas disease is a serious health problem in endemic Latin America countries; an estimated six million people are infected with Trypanossoma cruzi, leading to significant morbidity and mortality. Due to migratory waves, infected individuals have spread worldwide. Chronic Chagas' cardiomyopathy (CC) is the most severe and frequent manifestation, occurring in 25-30\% of all infected people. ${ }^{69}$ Patients may develop severe clinical manifestations, such as congestive HF, malignant arrhythmias, or thromboembolism. Chronic CC carries a worse prognosis when compared to ischemic and nonischemic HF. ${ }^{70}$ The presence of persistent myocardial inflammation plays a central role in the genesis of arrhythmias due to irreversible cell damage, fibrosis, and scar formation. Ventricular arrhythmias are a major cause of morbidity and mortality in patients with Chagas disease and may occur even before significant LV systolic dysfunction, leading to SCD. ${ }^{71}$

Miranda et al. showed that regional myocardial sympathetic denervation assessed with ${ }^{123}$ I-MIBG SPECT is associated with sustained VT in CC, concluding that viable, although denervated, myocardial areas were associated with the genesis of sustained ventricular arrhythmias. ${ }^{72}$ Furthermore, researchers have been searching for active inflammation as a trigger for 
reentry and VT. In this scenario, ${ }^{18}$ F-FDG PET may be a promising tool to monitor disease activity and risk stratification of patients with CC. Future studies should address these new potential clinical applications of PET imaging $^{73,74}$ (Figure 6).

\section{Limitation of the studies}

Some limitations affect the quality of our review on autonomic innervation evaluation in cardiac disease, such as the lack of prospective multicenter studies and the heterogeneity of the studies for autonomic dysfunction assessment in the diverse cardiac syndromes.

\section{Conclusions}

The autonomic nervous system plays a central role in the cardiac function. Cardiac neuronal imaging can be used to visualize the sympathetic innervation of the heart and allows for the early detection of these abnormalities caused by, for example, ischemia, heart failure, cardiomyopathies, cardiotoxicity, and arrhythmogenic disorder.

It is important to continue research in the field of cardiac autonomic innervation evaluation while exploring its clinical utility, as it has the potential to provide novel insights into pathophysiology of this cardiac disease and potentially lead to the development of novel therapies to improve prognoses.

\section{Author contributions}

Conception and design of the research: Xavier de Brito AS. Acquisition of data: Xavier de Brito, AS, Glavam A, Bronchtein AI. Analysis and interpretation of the data: Xavier de Brito AS, Rosado-de-Castro PH. Statistical analysis: Xavier de Brito AS, Rosado-de-Castro PH. Writing of the manuscript: Xavier de Brito AS, Glavam A. Critical revision of the manuscript for intellectual content: Rosado-de-Castro PH.

\section{Potential Conflict of Interest}

No potential conflict of interest relevant to this article was reported.

\section{Sources of Funding}

There were no external funding sources for this study.

\section{Study Association}

This article is part of the doctorate research of Adriana Soares Xavier de Brito from the D'Or Institute for Research and Education (IDOR), Rio de Janeiro - RJ, Brazil.

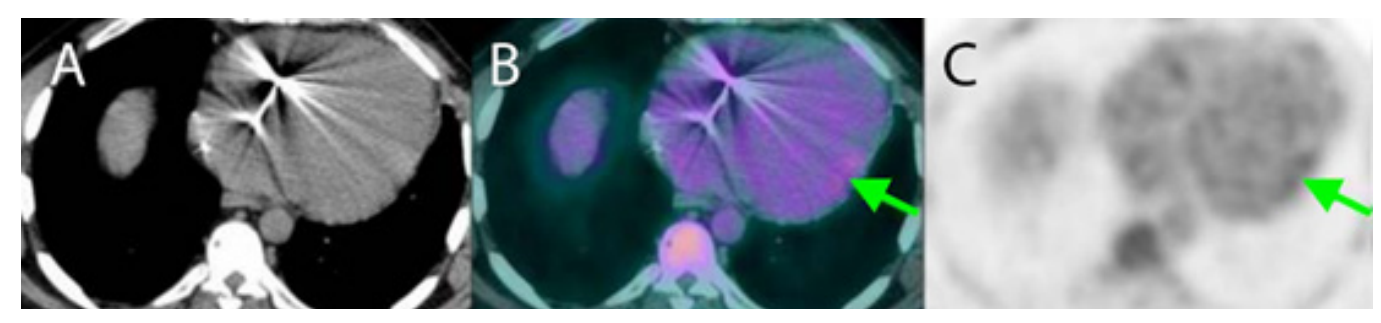

Figure $6-{ }^{18}$ F-FDG PET-CT in a patient with chagasic cardiomyopathy and pacemaker (A, axial CT; B, axial PET-CT; C, axial PET). Mild uptake was observed in the basal anterolateral segment. This finding could potentially indicate mild ventricular inflammation. 


\section{References}

1. Chugh SS, Reinier K, Teodorescu C, Evanado A, Kehr E, Al Samara M, et al. Epidemiology of sudden cardiac death: clinical and research implications. Prog Cardiovasc Dis. 2008;51(3):213-28.

2. Wehrwein EA, Orer HS, Barman SM. Overview of the anatomy, physiology, and pharmacology of the autonomic nervous system. Compr Physiol. 2016 Jun 13;6(3):1239-78.

3. Lymperopoulos A, Rengo G, Koch WJ.Adrenal adrenoceptors in heart failure: fine-tuning cardiac stimulation. Trends Mol Med. 2007;13(12):503-11.

4. Bengel FM. Imaging targets of the sympathetic nervous system of the heart: translational considerations. J Nucl Med. 2011;52(8):1167-70.

5. Lymperopoulos A, Rengo G, Koch WJ. Adrenergic nervous system in heart failure: pathophysiology and therapy. Circ Res. 2013;113(6):739-53.

6. Goldberger JJ, Arora R, Buckley U, Shivkumar K. Autonomic nervous system dysfunction: JACC Focus Seminar. J Am Coll Cardiol. 2019 Mar 19;73(10):1189-206.

7. Vaseghi M, Barwad P, Corrales FJM, Tandri H, Mathuria N, Shah R, et al. Cardiac sympathetic denervation for refractory ventricular arrhythmias. J Am Coll Cardiol. 2017;69(25):3070-80.

8. Nakajo M, Shapiro B, Copp J, Kalff V, Gross MD, Sisson JC, et al. The normal and abnormal distribution of the adrenomedullary imaging agent $\mathrm{m}-\mathrm{I} 123$ iodobenzylguanidine (I-123 MIBG) in man: evaluation by scintigraphy. J Nucl Med. 1983;24(8):672-82.

9. Carrió I. Cardiac neurotransmission imaging. J Nucl Med. 2001;42(7):1062-76.

10. Knuuti J, Sipola P. Is it time for cardiac innervation imaging? QJ Nucl Med Mol Imaging. 2005;49(1):97-105.

11. Agostini D, Carrió I, Verbene HJ. How to use myocardial 123I-MIBG scintigraphy in chronic heart failure. Eur J Nucl Med Mol Imaging. 2009;36(4):555-9.

12. Matsunari I, Aoki H, Nomura Y, Takeda N, Chen WP, Taki J, et al. Iodine-123 metaiodobenzylguanidine imaging and carbon-11 hydroxyephedrine positron emission tomography compared in patients with left ventricular dysfunction. Circ Cardiovasc Imaging. 2010;3(5):595-603.

13. Naya M, Tsukamoto T, Morita K, Katoh C, Nishijima K, Komatsu H, et al. Myocardial beta-adrenergic receptor density assessed by 11C-CGP12177 PET predicts improvement of cardiac function after carvedilol treatment in patients with idiopathic dilated cardiomyopathy. J Nucl Med. $2009 ; 50(2): 220-5$.

14. Jong RM, Willemsen ATM, Slart RHJA, Blanksma PK, Waarde A, Cornel JH, et al. Myocardial beta-adrenoceptor downregulation in idiopathic dilated cardiomyopathy measured in vivo with PET using the new radioligand (S)-[11C]CGP12388. Eur J Nucl Med Mol Imaging. 2005;32(4):443-7.

15. Schwaiger M, Kalff V, Rosenspire K, Haka MS, Molina E, Hutchins GD, et al. Noninvasive evaluation of sympathetic nervous system in human heart by positron emission tomography. Circulation. 1990;82(2):457-64.

16. Kaye DM, Lefkovits J, Jennings GL, Bergin P, Broughton A, Esler MD. Adverse consequences of high sympathetic nervous activity in the failing human heart. J Am Coll Cardiol. 1995;26(5):1257-63.

17. Franciosi S, Perry FKG, Roston TM, Armstrong KR, Claydon VR, Sanatani $\mathrm{S}$. The role of the autonomic nervous system in arrhythmias and sudden cardiac death. Auton Neurosci. 2017 Jul;205:1-11.

18. Packer M. The neurohumoral hypothesis: a theory to explain the mechanism of disease progression in patients with chronic heart failure. J Am Coll Cardiol. 1992;20(1):248-54.

19. Lefkwitz RJ, Rockman HA, Koch WJ. Catecholamines, cardiac betaadrenergic receptors, and heart failure. Circulation. 2000;101(14):1634-7.

20. Mann DL. Tumor necrosis factor-induced signal transduction and left ventricular remodeling. J Card Fail. 2002;8(6 Suppl):S379-86.

21. Kang PM, Izumo S. Apoptosis in heart: basic mechanisms and implications in cardiovascular diseases. Trends Mol Med. 2003;9(4):177-82.
22. Agostini D, Carrió I, Verbene HJ. How to use myocardial 123I-MIBG scintigraphy in chronic heart failure. Eur J Nucl Med Mol Imaging. 2009;36(4):555-9.

23. Kasama S, Toyama T, Takashi H, Sumino H, Kumakura H, Takayama Y, et al. Evaluation of cardiac sympathetic nerve activity and left ventricular remodeling in patients with dilated cardiomyopathy on the treatment containing carvedilol. Eur Heart J. 2007;28(8):989-95.

24. Henneman MM, Bax JJ, Wall EE. Monitoring of therapeutic effect in heart failure patients: a clinical application of 123I MIBG imaging. Eur Heart J. 2007;28(8):922-3.

25. Nakata T, Miyamoto K, Doi A, Sasao H, Wakabayshi T, Kobatashi H, et al. Cardiac death prediction and impaired cardiac sympathetic innervation assessed by MIBG in patients with failing and nonfailing hearts. J Nucl Cardiol. 1998;5(6):579-90.

26. Nakata T, Nakajima K, Yamashina S, Yamada T, Momose M, Kasama S, et al. A Pooled Analysis of Multicenter Cohort Studies of (123)I-mIBG Imaging of Sympathetic Innervation for Assessment of Long-Term Prognosis in Heart Failure. JACC Cardiovasc Imaging. 2013 Jul;6(7):772-84.

27. Gill JS, Hunter GJ, Gane J, Ward DE, Camm AJ. Asymmetry of cardiac [123I] meta-iodobenzyl-guanidine scans in patients with ventricular tachycardia and a "clinically normal" heart. Br Heart J. 1993;69(1):6-13.

28. Merlet P, Benvenuti C, Moyse D, Pouillart F, Dubois-Randé JL, Duval AM, et al. Prognostic value of MIBG imaging in idiopathic dilated cardiomyopathy. J Nucl Med. 1999;40(6):917-23.

29. Agostini D, Verberne HJ, Burchert W, Knnuti J, Povinec P, Sambuceti $\mathrm{G}$, et al. I-123-mIBG myocardial imaging for assessment of risk for a major cardiac event in heart failure patients: insights from a retrospective European multicenter study. Eur J Nucl Med Mol Imaging. 2008;35(3):535-46.

30. Verberne HJ, Brewster LM, Somsen GA, Eck-Smit BLF. Prognostic value of myocardial 123I-metaiodobenzylguanidine (MIBG) parameters in patients with heart failure: a systematic review. Eur Heart J. 2008;29(9):1147-59.

31. Verschure DO, Veltman CE, Manrique A, Somsen GA, Koutelou M, Katsikis K, et al. For what endpoint does myocardial 123I-MIBG scintigraphy have the greatest prognostic value in patients with chronic heart failure? Results of a pooled individual patient data meta-analysis. Eur Heart J Cardiovasc Imaging. 2014;15(9):996-1003.

32. Gerson MC, Craft LL, McGuire N, Suresh DP, Abraham WT, Wagoner LE. Carvedilol improves left ventricular function in heart failure patients with idiopathic dilated cardiomyopathy and a wide range of sympathetic nervous system function as measured by iodine-123 metaiodobenzylguanidine. J Nucl Cardiol. 2002;9(6):608-15.

33. Somsen GA, Vlies B, Milliano PA, Borm JJ, Royen EA, Endert E, et al. Increased myocardial [123-I]- metaiodobenzylguanidine uptake after enalapril treatment in patients with chronic heart failure. Heart. 1996;76(3):218-22.

34. Kasama S, Toyama T, Kumakura H, Takayama Y, Ichikawa S, Suzuki T, et al. Effect of spironolactone on cardiac sympathetic nerve activity and left ventricular remodeling in patients with dilated cardiomyopathy. J Am Coll Cardiol. 2003;41(4):574-81.

35. Fujimoto $S$, Inoue A, Hisatake $S$, Yamashina $S$, Yamashina $H$, Nakano $\mathrm{H}$, et al. Usefulness of (123) I-meta-iodo-benzyl-guanidine myocardial scintigraphy for predicting the effectiveness of beta-blockers in patients with dilated cardiomyopathy from the standpoint of long-term prognosis. Eur J Nucl Med Mol Imaging. 2004;31(10):1356-61.

36. Gould PA, Kong G, Kalff V, Duffy SJ, Taylor AJ, Kelly MJ, et al. Improvement in cardiac adrenergic function post biventricular pacing for heart failure. Europace. 2007;9(9):751-6.

37. Messias LR, Carreira AMQ, Miranda SM, Azevedo JC, Gava IA, Rodrigues RC, et al. Is abnormal adrenergic activation associated with abnormal heart rate recovery? Arq Bras Cardiol. 2012;98(5):398-405. 
38. Kioka H, Yamada T, Mine T, Morita T, Tsukamoto Y, Tamaki S, et al. Prediction of sudden death in patients with mild-moderate chronic heart failure by using cardiac iodine-123-metaiodo-benzyl-guanidine imaging. Heart. 2007;93(10):1213-18

39. Arora R, Ferrick KJ, Nakata T, Kaplan R, Rozengarten M, Latif F, et al. 123IMIBG imaging and heart rate variability analysis to predict the need for implantable cardioverter defibrillator. J Nucl Cardiol. 2003;10(2):121-31.

40. Akutsu Y, Kaneko K, Kodama Y, Li HL, Kawamura M, Asano T, et al. The significance of cardiac sympathetic nervous system abnormality in the longterm prognosis of patients with a history of ventricular tachyarrhythmia. J Nucl Med. 2009;50(1):61-7.

41. Jacobson AF, Senior R, Cerqueira MD, Wong ND, Thomas GS, Lopez VA, et al. ADMIRE-HF investigators. Myocardial iodine-123 metaiodobenzylguanidine imaging and cardiac events in heart failure. Results of the prospective ADMIRE-HF (AdreView Myocardial Imaging for Risk Evaluation in Heart Failure) study. J Am Coll Cardiol. 2010;55(20):2212-21.

42. Dae MW, O'Connell JW, Botvinick E, Chin MC. Acute and chronic effects of transient myocardial ischemia on sympathetic nerve activity, density, and norepinephrine content. Cardiovasc Res. 1995;30(2):270-80.

43. Zipes DP. Sympathetic stimulation and arrhythmias. N Engl J Med. 1991;325(9):656-7.

44. Klein T, Abdulghani M, Smith M, Huang R, Asoglu R, Remo BF, et al. Threedimensional 123I-meta-iodobenzylguanidine cardiac innervation maps to assess substrate and successful ablation sites for ventricular tachycardia: feasibility study for a novel paradigm of innervation imaging. Circ Arrhythm Electrophysiol. 2015;8(3):583-91.

45. Fallavollita JA, Heavey BM, Luisi Jr AJ, Michalek SM, Baldwa S, Mashtare TS, et al. Regional myocardial sympathetic denervation predicts the risk of sudden cardiac arrest in ischemic cardiomyopathy. J Am Coll Cardiol. 2014;63(2):141-9.

46. Ibánez B, James S, Agewall S, Antunes MJ, Bucciarelli-Ducci C, Bueno H, et al. 2017 ESC Guidelines for the management of acute myocardial infarction in patients presenting with ST-segment elevation. Rev Esp Cardiol(Engl Ed). 2017;70(12):1082.

47. Zipes DP. Influence of myocardial ischemia and infarction on autonomic innervation of heart. Circulation. 1990;82(4):1095-105.

48. Nagahara D, Nakata T, Hashimoto A, Wakabayashi T, Kyuma M, Noda $\mathrm{R}$, et al. Predicting the need for an implantable cardioverter defibrillator using cardiac metaiodobenzylguanidine activity together with plasma natriuretic peptide concentration or left ventricular function. J Nucl Med. 2008;49(2):225-33.

49. Nishisato K, Hashimoto A, Nakata T, Doi T, Yamamoto H, Nagahara D, et al. Impaired cardiac sympathetic innervation and myocardial perfusion are related to lethal arrhythmia: quantification of cardiac tracers in patients with ICDs. J Nucl Med. 2010;51(8):1241-9.

50. Boogers MJ, Borleffs JWC, Henneman MM, Bommel RJ, Ramshorst J, Boersma E, et al. Cardiac sympathetic denervation assessed with 123-iodine metaiodobenzylguanidine imaging predicts ventricular arrhythmias in implantable cardioverter-defibrillator patients. J Am Coll Cardiol. 2010;55(24):2769-77.

51. Chazal HM, Del Buono MG, Keyser-Marcus L, Ma L, Moeller FG, Berrocal D, et al. Stress cardiomyopathy diagnosis and treatment: JACC State-of-the-Art Review. J Am Coll Cardiol. 2018;72(16):1955-71.

52. Ghadri JR, Wittstein IS, Prasad A, Sharkey S, Dote K, Akashi YJ, et al International Expert Consensus Document on Takotsubo Syndrome (Part I): clinical characteristics, diagnostic criteria, and pathophysiology. Eur Heart J. 2018;39(22):2032-46.

53. Manabe O, Naya M, Oyama-Manabe N, Koyanagawa K, Tamaki N. The role of multimodality imaging in takotsubo cardiomyopathy. J Nucl Cardiol. 2019;26(5):1602-16.

54. Bossone E, Lyon A, Citro R, Athanasiadis A, Meimoun P, Parodi G, et al. Takotsubo cardiomyopathy: An integrated multi-imaging approach. Eur Heart J Cardiovasc Imaging. 2014;15(4):366-7.

55. Verschure DO, Eck-Smit BLF, Somsen GA, Verberne HJ. Cardiac sympathetic activity in hypertrophic cardiomyopathy and Tako-tsubo cardiomyopathy. Clin Transl Imaging. 2015;3(5):379-85.
56. Christensen TE, Bang LE, Holmvang L, Skovgaard DC, Oturai DB, Søholm $\mathrm{H}$, et al. 123I-MIBG Scintigraphy in the subacute state of Takotsubo cardiomyopathy. JACC Cardiovasc Imaging. 2016;9(8):982-90.

57. Lyon AR, Bossone E, Schneider B, Sechtem U, Citro R, Underwood SR, et al Current state of knowledge on Takotsubo syndrome: a position statement from the taskforce on takotsubo syndrome of the Heart Failure Association of the European Society of Cardiology. Eur J Heart Fail. 2016;18(1):8-27.

58. Madias JE. Do we need MIBG in the evaluation of patients with suspected Takotsubo syndrome? Diagnostic, prognostic, and pathophysiologic connotations. Int J Cardiol. 2016 Jan 15;203:783-4.

59. Geske JB, Ommen SR, Gersh BJ. Hypertrophic cardiomyopathy: clinical update. JACC Hear Fail. 2018;6(5):364-75.

60. Elliott PM, Anastasakis A, Borger MA, Borggrefe M, Cecchi F, Charron P, et al. 2014 ESC guidelines on diagnosis and management of hypertrophic cardiomyopathy: The task force for the diagnosis and management of hypertrophic cardiomyopathy of the European Society of Cardiology (ESC). Eur Heart J. 2014;35(39):2733-79.

61. Gersh BJ, Maron BJ, Bonow RO, Dearani JA, Fifer MA, Link MS, et al. 2011 ACCF/AHA guideline for the diagnosis and treatment of hypertrophic cardiomyopathy: a report of the American College of Cardiology Foundation/ American Heart Association task force on practice guidelines. Circulation. 2011;124(24):783-831.

62. Shirani J, Dilsizian V. Nuclear cardiac imaging in hypertrophic cardiomyopathy. J Nucl Cardiol. 2011;18(1):123-34.

63. Chen-Scarabelli C, McRee C, Leesar MA, Hage FG, Scarabelli TM. Comprehensive review on cardio-oncology: role of multimodality imaging. J Nucl Cardiol. 2017;24(3):906-35.

64. Kahanda MG, Hanson CA, Patterson B, Bourque JM. Nuclear cardiooncology: from its foundation to its future. J Nucl Cardiol. 2020;27(2):511-8.

65. Soufer A, Liu C, Henry ML, Baldassarre LA. Nuclear cardiology in the context of multimodality imaging to detect cardiac toxicity from cancer therapeutics: established and emerging methods. J Nucl Cardiol.. 2019;27(4):1210-24.

66. Geus-Oei LF, Mavinkurve-Groothuis AMC, Bellersen L, Gotthardt M, Oyen WJG, Kapusta L, et al. Scintigraphic techniques for early detection of cancer treatment-induced cardiotoxicity. J Nucl Med Technol. 2013;41(3):170-81.

67. Verberne HJ, Verschure DO. Anthracycline-induced cardiotoxicity: Is there a role for myocardial 123I-mIBG scintigraphy? J Nucl Cardiol. 2020;27(3):940-2.

68. Russell RR, Alexander J, Jain D, Poornima IG, Srivastava A V, Storozynsky $\mathrm{E}$, et al. The role and clinical effectiveness of multimodality imaging in the management of cardiac complications of cancer and cancer therapy. J Nucl Cardiol. 2016;23(4):856-84.

69. Requena-Méndez A, Aldasoro E, Lazzari E, Sicuri E, Brown M, Moore DAJ, et al. Prevalence of Chagas disease in Latin-American migrants living in Europe: a systematic review and meta-analysis. PLoS Negl Trop Dis. 2015;9(2):e0003540

70. Shen L, Ramires F, Martinez F, Bodanese LC, Echeverría LE, Gómez EA et al. Contemporary characteristics and outcomes in chagasic heart failure compared with other nonischemic and ischemic cardiomyopathy. Circ Heart Fail. 2017;10(11):e004361.

71. Landesmann MCP, Fonseca LMB, Pereira BB, Nascimento EM, Rosado-deCastro PH, Souza SAL, et al. Iodine-123 metaiodobenzylguanidine cardiac imaging as a method to detect early sympathetic neuronal dysfunction in chagasic patients with normal or borderline electrocardiogram and preserved ventricular function. Clin Nucl Med. 2011;36(9):757-61.

72. Miranda, C.H, Figueiredo, AB, Maciel, BC, Marin-Neto JA, Simoes, MV, Sustained ventricular tachycardia is associated with regional myocardial sympathetic denervation assessed with 123I-metaiodobenzylguanidine in chronic Chagas cardiomyopathy. J Nucl Med. 2011;52(4):504-10.

73. Moll-Bernardes RJ, Rosado-de-Castro PH, Camargo GC, Mendes FSNS, Brito ASX, Sousa AS. New imaging parameters to predict sudden cardiac death in Chagas disease. Trop Med Infect Dis. 2020 May 8;5(2):74.

74. Simoes MV, Gadioli LP, Oliveira LFL. Radionuclide imaging in Chagas cardiomyopathy. Curr Cardiovasc Imaging Rep. 2019;12(7):1-8. 